\title{
Tensile and Impact Toughness Properties of a Zr-Based Bulk Metallic Glass Fabricated via Laser Powder-Bed Fusion
}

\author{
Navid Sohrabi ${ }^{1, *(\mathbb{D}}$, Annapaola Parrilli ${ }^{2} \mathbb{D}$, Jamasp Jhabvala ${ }^{1}$, Antonia Neels ${ }^{2} \mathbb{D}$ and Roland E. Logé ${ }^{1}$ (D) \\ 1 Thermomechanical Metallurgy Laboratory, PX Group Chair, Ecole Polytechnique Fédérale de \\ Lausanne (EPFL), 2002 Neuchâtel, Switzerland; jamasp.jhabvala@epfl.ch (J.J.); roland.loge@epfl.ch (R.E.L.) \\ 2 Center for X-ray Analytics, Swiss Federal Laboratories for Materials Science and Technology (Empa), \\ Überlandstrasse 129, 8600 Dübendorf, Switzerland; annapaola.parrilli@empa.ch (A.P.); \\ antonia.neels@empa.ch (A.N.) \\ * Correspondence: navid.sohrabi@epfl.ch
}

Citation: Sohrabi, N.; Parrilli, A.; Jhabvala, J.; Neels, A.; Logé, R.E. Tensile and Impact Toughness

Properties of a Zr-Based Bulk Metallic Glass Fabricated via Laser Powder-Bed Fusion. Materials 2021 14, 5627. https://doi.org/10.3390/ ma14195627

Academic Editor: Jason

Shian-Ching Jang

Received: 27 August 2021

Accepted: 25 September 2021

Published: 27 September 2021

Publisher's Note: MDPI stays neutral with regard to jurisdictional claims in published maps and institutional affiliations.

Copyright: (c) 2021 by the authors. Licensee MDPI, Basel, Switzerland. This article is an open access article distributed under the terms and conditions of the Creative Commons Attribution (CC BY) license (https:// creativecommons.org/licenses/by/ $4.0 /)$.
Abstract: In the past few years, laser powder-bed fusion (LPBF) of bulk metallic glasses (BMGs) has gained significant interest because of the high heating and cooling rates inherent to the process, providing the means to bypass the crystallization threshold. In this study, (for the first time) the tensile and Charpy impact toughness properties of a Zr-based BMG fabricated via LPBF were investigated. The presence of defects and lack of fusion $(\mathrm{LoF})$ in the near-surface region of the samples resulted in low properties. Increasing the laser power at the borders mitigated LoF formation in the nearsurface region, leading to an almost $27 \%$ increase in tensile yield strength and impact toughness. Comparatively, increasing the core laser power did not have a significant influence. It was therefore confirmed that, for BMGs like for crystalline alloys, near-surface LoFs are more detrimental than core LoFs. Although increasing the border and core laser power resulted in a higher crystallized fraction, detrimental to the mechanical properties, reducing the formation of LoF defects (confirmed using micro-computed tomography, Micro-CT) was comparatively more important.

Keywords: bulk metallic glass (BMG); laser powder-bed fusion (LPBF); crystallization; defects; tensile properties; impact toughness

\section{Introduction}

Bulk metallic glasses (BMGs) have gained tremendous attention during the last two decades due to their exceptional properties, such as high strength and elastic limit, good corrosion, and wear resistance. However, the main drawback that prevents widespread use of BMGs are their low ductility and size limitation [1].

In BMGs, plastic deformation is confined in shear bands with a nanoscale width, which is then followed by rapid propagation, and finally abrupt rupture [2]. Szuecs et al. [3] improved the low ductility of a Zr-based BMG by introducing a soft crystalline phase and creating a BMG composite with 5.5\% ductility in tension. Ning et al. [4] introduced a new approach for achieving ductility in tension without losing the strength of a CuZr-based BMG composite significantly: a B2-CuZr phase formed in the BMG composite and led to deformation-induced martensitic transformation, resulting in $7 \%$ ductility.

BMGs have a very low (<2 J) impact toughness [5-11]. Nagendra et al. [5] reported $90 \%$ decrease in the impact toughness of a La-based BMG upon partial crystallization. Roberts et al. [11] could increase the impact toughness of a Zr-based BMG from $0.82 \mathrm{~J}$ to $2.66 \mathrm{~J}$ by introducing a $67 \mathrm{vol} \%$ ductile crystalline phase. Several studies showed that annealing below the glass transition temperature $\left(T_{\mathrm{g}}\right)$ of the alloy deteriorates the impact toughness of the BMG due to relaxation and annihilation of the free volume [6-9]. Another factor reported to be detrimental to the toughness (impact and fracture) of BMGs is the oxygen content [12-14]. 
Although there are some well-established techniques to fabricate BMGs, such as casting and melt spinning, they are not applicable for the fabrication of large size BMGs sensitive to crystallization. For instance, Bordeenithikasem et al. [15] failed to cast large parts from an industrial-grade (high oxygen content) Zr-based metallic glass called AMZ4. They could fabricate large parts with acceptable mechanical properties using laser powderbed fusion (LPBF). LPBF is the most studied laser-based additive manufacturing (AM) process $[16,17]$. It leads to extremely high cooling rates $\left(10^{4}-10^{6} \mathrm{~K} / \mathrm{s}\right)$ due to local and short interaction between the laser and the powder [18]; these are higher than most BMG's critical cooling rates [19]. Therefore, LPBF provides an excellent opportunity to overcome the size limitation of traditional BMG fabrication methods. Different BMGs based on $\mathrm{Pd}$ [20], $\mathrm{Al}$ [21], $\mathrm{Cu}$ [22], Ti [23], Fe [24-26], and Zr [27-32] have been processed via LPBF during the last eight years.

Reported works on LPBF of BMG have mainly focused on microstructural evaluation $[27,29]$, crystallization mechanisms [26,27,29], parameters optimization [25,29], and mechanical properties $[27,29,30]$ such as compressive and flexural strength, hardness, and wear resistance. Only one study, Best et al. [33], investigated the tensile properties of a Zr-based BMG fabricated via LPBF. They blamed the presence of defects such as lack of fusion (LoF) for the calamitous failure. They did not increase the input energy, which could decrease the formation of LoFs, to prevent crystallization. Tensile properties of BMGs, and BMG composites fabricated with another laser-based AM process, i.e., direct energy deposition (DED) [34-37] have been previously investigated. However, to the best of our knowledge, the influence of defects on the impact toughness of BMGs fabricated via AM has not been reported so far.

In the present work, we investigate the tensile properties and impact toughness of a Zr-based BMG (ZrCuAlNb, free of Ni and Be, called AMZ4) produced via LPBF. LoFs are the main reason for the premature failure of the specimens. Two strategies are investigated for changing laser power at the border/contour and in the core of the sample, with the aim of increasing the tensile strength and impact toughness. The effect of border power is shown to be more significant than core parameters. Although the two strategies result in increased detrimental crystallization in AMZ4, the elimination/mitigation of defects remains the key element for property improvement.

\section{Materials and Methods}

In this work, an industrial-grade Zr-based metallic glass (AMZ4) powder with a nominal chemical composition of $\mathrm{Zr}_{59.3} \mathrm{Cu}_{28.8} \mathrm{Al}_{10.4} \mathrm{Nb}_{1.5}$ (at.\%) and particle size distribution ranging from $10 \mu \mathrm{m}$ to $50 \mu \mathrm{m}\left(\mathrm{D}_{50}=30 \mu \mathrm{m}\right)$, supplied by Heraeus $\mathrm{GmbH}$ was used. A TruPrint 1000 machine $(\varphi 30 \mu \mathrm{m})$ was used for the fabrication of the samples in an Ar atmosphere. The processing parameters used for the fabrication of tensile and impact specimens on an Al-Mg-Si1 substrate are mentioned in Table 1 and Figure 1a defines the notions of border/contour, core, and hatching distance. An island scanning strategy with an island size of $4 \times 4 \mathrm{~mm}^{2}$ and a $90^{\circ}$ orientation change after each layer was used for printing specimens for tensile and impact tests.

Table 1. Printing parameters used for the fabrication of tensile and impact specimens. The notions of "core" and "border" are illustrated in Figure 1a.

\begin{tabular}{cccccc}
\hline Set & $\begin{array}{c}\text { Core Power } \\
(\mathbf{W})\end{array}$ & $\begin{array}{c}\text { Scanning } \\
\text { Speed }(\mathbf{m m} / \mathbf{s})\end{array}$ & $\begin{array}{c}\text { Hatching } \\
\text { Distance }(\boldsymbol{\mu m})\end{array}$ & $\begin{array}{c}\text { Layer Thickness } \\
(\boldsymbol{\mu m})\end{array}$ & $\begin{array}{c}\text { Border } \\
\text { Power }(\mathbf{W})\end{array}$ \\
\hline A & 30 & 600 & 90 & 20 & 30 \\
B & 30 & 600 & 90 & 20 & 42 \\
C & 36 & 600 & 90 & 20 & 42 \\
\hline
\end{tabular}


(a)
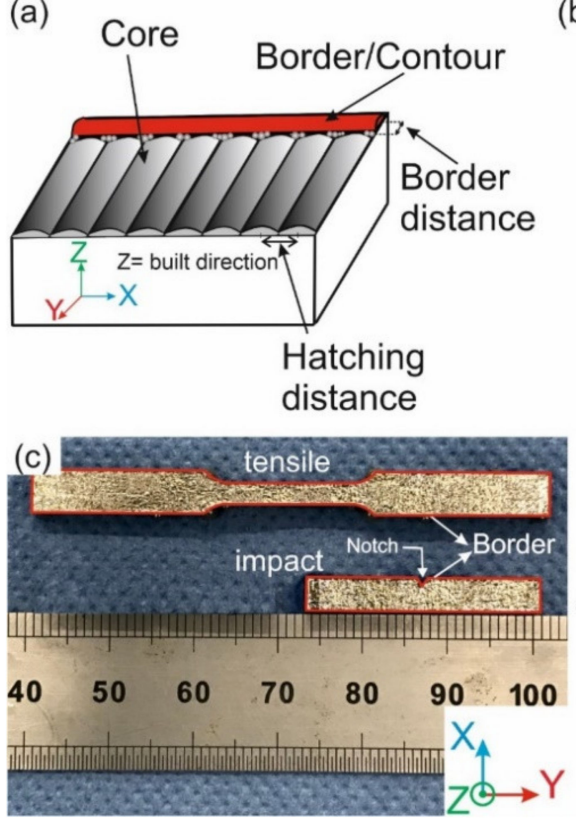

(b)

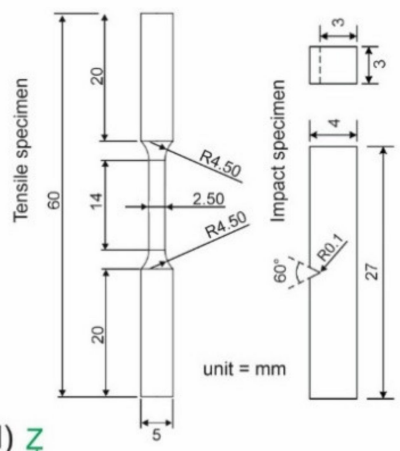

(d) $z$

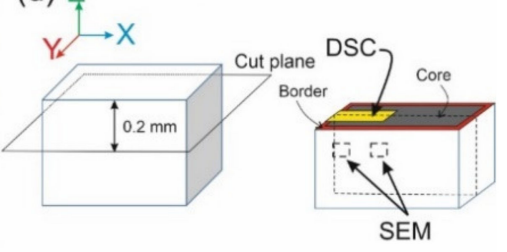

Figure 1. (a) Schematic view of laser scanning showing the notions of border, core, hatching distance, and border distance for a part of a sample, (b) geometry of the tensile and impact specimens, (c) a tensile and an impact specimen fabricated via LPBF, and (d) schematic view of the samples showing locations of SEM and DSC analyses with respect to the core and border regions.

The geometries of the fabricated specimens (tensile, based on ASTM E8, and impact, based on ISO 14556) are given in Figure 1b. For each Set described in Table 1, three tensile specimens with a thickness of $2.5 \mathrm{~mm}$ and six impact specimens were printed. Figure $1 \mathrm{c}$ shows one tensile and one impact specimen fabricated via LPBF. The notch of the impact specimens was designed in the CAD file introduced to the LPBF machine. The notch radius was measured as $0.11 \mathrm{~mm}$ in the fabricated specimens, slightly larger than the nominal value $(0.10 \mathrm{~mm})$. The border region is shown in red color in Figure 1c, and the notch of the impact specimens is surrounded by material scanned with border parameters (in each layer, through the fabrication process). The specimens were milled from one side to remove the support structure; they were then tested in "semi-as-built" condition.

To study the microstructure and fractography, a FESEM (ZEISS GeminiSEM450) was utilized. X-ray diffraction (XRD), using a PanAlytical Empyrean diffractometer with $\mathrm{Cu}$ $K \alpha$ radiation, was employed to check the amorphous nature of fabricated parts. It was performed on the $\mathrm{X}-\mathrm{Y}$ cross-section of the printed sample around $0.2 \mathrm{~mm}$ below the top surface, which is ten times the LPBF layer thickness $(20 \mu \mathrm{m})$. At this depth, the material has been subjected to several thermal cycles, similar to those experienced in the bulk. The crosssection includes both core and border regions. Differential scanning calorimetry (DSC) tests were carried out in a Netzsch DSC $204 \mathrm{~F} 1$ Phoenix system using a heating rate of $20^{\circ} \mathrm{C} / \mathrm{min}$. To etch and reveal the microstructure of the printed specimens, they were cut, ground, and then polished with a suspension of alumina down to $1 \mu \mathrm{m}$ size and a solution of ( $45 \mathrm{~mL}$ water $+45 \mathrm{~mL} \mathrm{HNO}_{3}+10 \mathrm{~mL} \mathrm{HF}$ ) was used at room temperature. Figure $1 \mathrm{~d}$ shows the sample geometry and indicates the locations of SEM and DSC microstructure analyses.

Tensile tests were conducted in a Shimadzu AGS-20kNXD and a Schenck-Trebel universal tester, using a displacement rate of $0.5 \mathrm{~mm} / \mathrm{min}$ and a DSES-1000 Extensometer. Charpy impact tests (Charpy V-notch tests) were performed using an Amsler machine with a maximum energy of $10 \mathrm{~J}$. Both tests were performed at room temperature.

Micro-computed tomography (Micro-CT) analysis was carried out using an EasyTom XL Ultra 230-160 micro/nano-CT scanner (RX Solutions, Chavanod France). For more infor- 
mation concerning the Micro-CT analysis, please refer to [32]. To determine and select LoFs, the shape parameter was calculated in the Avizo software using the following formula:

$$
\text { Shape }=\frac{S^{3}}{36 \pi V^{2}}
$$

where $S$ is the 3D surface area of the pores and $V$ is the volume of the pores. The shape of 1 is considered a perfect sphere, and an increasing shape number leads to more complex convolute shapes [38]. Therefore, a shape $\geq 5$ was considered as the threshold for detecting LoFs.

\section{Results}

\subsection{Microstructure}

The parameters used for Set A, taken from Ref [27], led to a good combination of density and amorphous content, demonstrated by the resulting high compression and flexural strengths, and high wear resistance. The reason for using a border/contour scan was to improve the geometrical accuracy, as routinely done in LPBF [27,39].

The XRD patterns of printed specimens with the parameters mentioned in Table 1 are presented in Figure 2a. The Set A pattern shows a broad halo peak, which indicates an amorphous structure within the detection limit of XRD. The XRD pattern of Set $B$ shows tiny peaks, which indicates that the amount of crystallization reached a certain level, detectable by XRD. The intensity of crystalline peaks for Set $C$ in Figure 2a is even higher than for Set B. Analyzing the diffraction patterns, we observe overlapping peak domains of intermetallic phases and oxides. The phase analysis has been approached based on the peak indexing and following matching with the COD database. Samples B and C show, in addition to the amorphous hump originating from the amorphous part of the sample, the same diffraction peaks, hence the same crystalline phases. The dominant crystalline phase is $\mathrm{Al}_{2} \mathrm{Zr}$ (PDF No. 99-007-0065, orthorhombic Fdd2) followed by $\mathrm{ZrCu}$ (PDF No. 99007-0025, monoclinic $\mathrm{P} 2_{1} / \mathrm{m}$ ) and CuZr 2 (PDF No. 99-007-0022, 96-431-0035, tetragonal $\mathrm{I} 4 / \mathrm{mmm}$ ). The latter mentioned B2-type CuZr phases in precipitations of CuZr-based BMGs are seen as important for achieving high plasticity CuZr-based BMG composites [40]. Additionally, also $\mathrm{Cu}_{10} \mathrm{Zr}_{7}$ (PDF No. 99-007-0147, orthorhombic Aba2) and $\mathrm{Al}_{2} \mathrm{Zr}_{3}$ (PDF No. 99-007-0063, tetragonal $\mathrm{P} 4_{2} / \mathrm{mnm}$ ) could crystallize as quoted by other researchers previously [41]. In addition, as the starting powder material showed a high oxygen content, $\mathrm{CuO}$ (PDF No. 96-901-5842, monoclinic $\mathrm{C} 2 / \mathrm{c}$ ) and $\mathrm{Cu}_{2} \mathrm{Zr}_{4} \mathrm{O}$ can be identified [27,42]. $\mathrm{Cu}_{2} \mathrm{Zr}_{4} \mathrm{O}$ is a NiTi 2 -type phase exhibiting a cubic cell setting with space group $\mathrm{Fd}-3 \mathrm{~m}$ with a $=11.953-12.088 \AA$. However, the overlap of the different phases and the possible formation of solid solutions do not allow an unambiguous phase attribution.

DSC tests were performed to measure the amount of crystallization in the samples. The DSC curves of Set A, B and C samples are shown in Figure $2 b$, and quantified in Table 2. To calculate the amorphous fraction, the enthalpy of crystallization $(\Delta H)$ of the virgin powder, $86.9 \mathrm{~J} / \mathrm{g}$ in Ref [43], was used as a reference. The onset temperature of glass transition $\left(T_{\mathrm{g}}\right)$ and crystallization $\left(T_{\mathrm{x}}\right)$ of all three Sets is more or less the same, but the enthalpy of crystallization $(\Delta H)$ of the samples is different. Comparing $\Delta H$ to the reference value of the powder, the estimated amorphous fractions are $0.94,0.91$, and 0.83 for Set A, Set $B$, and Set $C$, respectively.

Figure 2c shows a back-scattered electron (BSE) image of the X-Z cross-section of Set A. The melt pool and HAZ are clearly detectable. Crystals with darker contrast are dispersed in the amorphous matrix of the HAZ (the light-colored rectangular features are due to contamination.). A higher magnification image (Figure 2d) shows that the crystals size is smaller than $500 \mathrm{~nm}$; they can be considered as nanocrystals. Supplementary Materials Figure S1a,b shows BSE images of the X-Z cross-section of Set B, in the core region. The width of the HAZ is similar to those of Set A (see Figure S1a,b), since core printing parameters are the same. However, they are more aggregated in the border region of Set B (see Figure S1c,d) because of the increased power in this zone. Figure S1e-h shows 
the melt pool of the core and border regions of Set C, respectively. As expected, in the core region, the width of the HAZ is larger and the nanocrystals are aggregated, due to the increased power. In the border region, the features are almost similar to the ones of Set B (see Figure S1c,d).
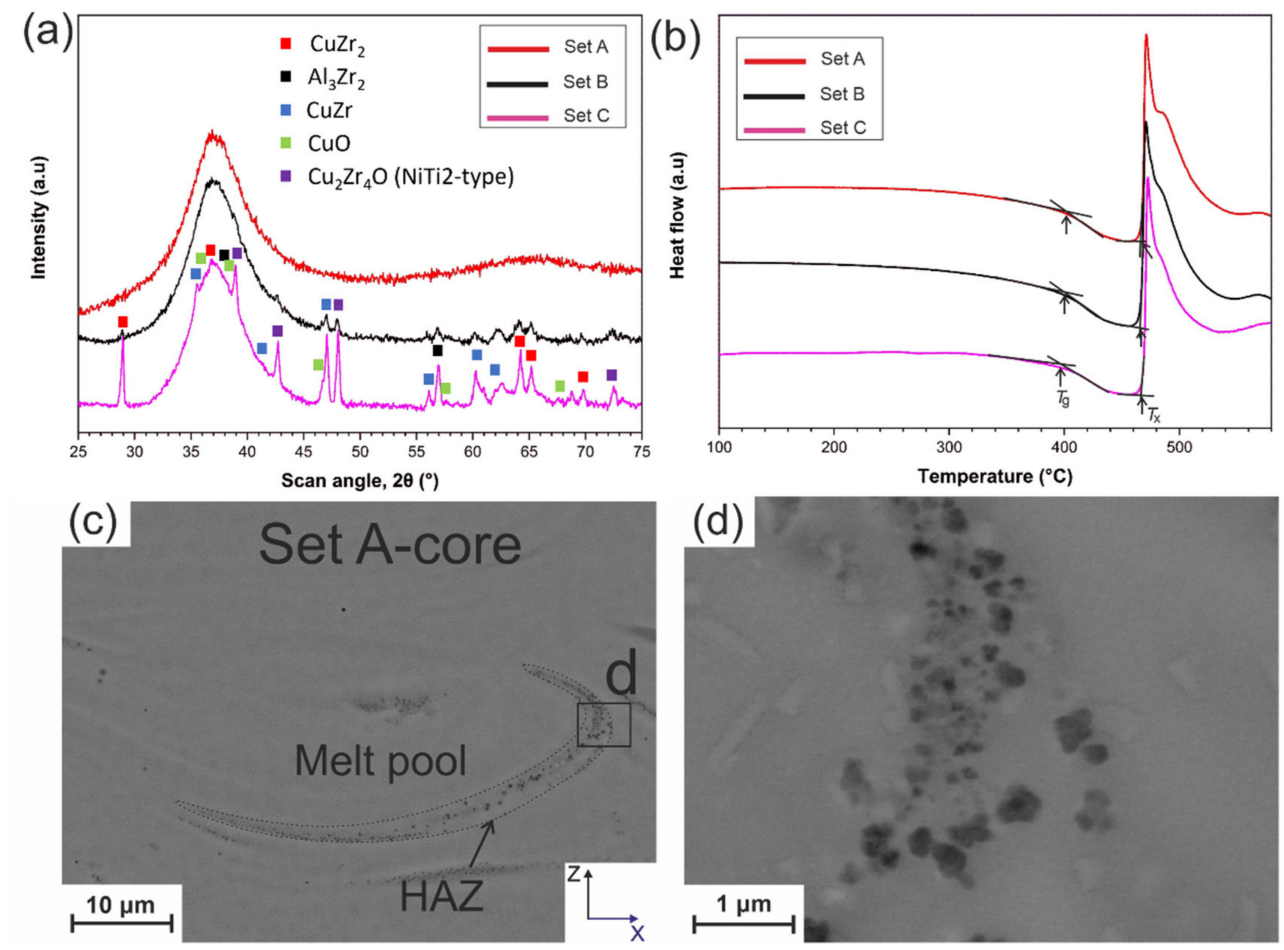

Figure 2. (a) XRD patterns of Sets A-C. (b) DSC results of the samples manufactured by Sets A-C parameters using a heating rate of $20^{\circ} \mathrm{C} / \mathrm{min}$, (c) back-scattered electron (BSE) image of the $\mathrm{X}-\mathrm{Z}$ cross-section of Set $\mathrm{A}$, and (d) higher magnification of region $\mathrm{d}$ in (c) indicating the presence of nanocrystals. The light-colored rectangular features are due to contamination.

Table 2. DSC results (using a heating rate of $20^{\circ} \mathrm{C} / \mathrm{min}$ ) of samples manufactured with Sets A-C parameters. The amorphous fraction is calculated by dividing the enthalpy of crystallization $(\Delta H)$ of each Set by the $\Delta H$ value of the virgin powder, which was $86.9 \mathrm{~J} / \mathrm{g}$ in Ref. [43].

\begin{tabular}{ccccc}
\hline Sample & $\boldsymbol{T}_{\mathbf{g}}\left({ }^{\circ} \mathbf{C}\right)$ & $\boldsymbol{T}_{\mathbf{x}}\left({ }^{\circ} \mathbf{C}\right)$ & $\boldsymbol{\Delta} \boldsymbol{H}(\mathbf{J} / \mathbf{g})$ & Amorphous Fraction \\
\hline Set A & 393.7 & 467.6 & 81.34 & 0.94 \\
Set B & 394.8 & 466.7 & 79.39 & 0.91 \\
Set C & 394.7 & 468.5 & 72.69 & 0.83 \\
\hline
\end{tabular}

\subsection{Impact Toughness}

The direction of the impact force was perpendicular to the building direction of the fabricated specimens. The impact toughness of Set A, Set B, and Set C are measured as $123 \pm 28 \mathrm{~mJ}, 158 \pm 19 \mathrm{~mJ}$, and $163 \pm 21 \mathrm{~mJ}$, respectively. Set B and Set $C$ showed better toughness than Set A, i.e., the strategy of changing the processing parameters was successful. The statistical scatter of the results is around $12 \%$.

The macrograph of the fracture surface of Set A is presented in Figure 3a, in which LoFs are indicated with yellow-dashed arrows. The systematic presence of LoFs is clearly visible in the near-surface region (see Figure 3b), which corresponds to the intersection of border and core regions (see powder particles trapped in the region between core and border regions in the schematic of Figure 1a). It can be concluded that the border laser power was not high enough to fully melt the powder in that region and resulted in LoF formation. Two easily detectable LoFs were detected in the core of Set B (see Figure 3c) 
because it has the same parameters as Set A (see Figure 3a). Increasing the border power (Set $B$ ) shows promising results in the reduction in the number and size of near-surface LoFs (see Figure 3d) compared to Set A. The fracture surface of Set C in Figure 3e displays no presence of LoFs in the near-surface and core regions. It, therefore, indicates that the increase of core power effectively prevented the formation of LoFs in the core region. However, an open-to-surface porosity (Figure $3 \mathrm{f}$ ) could be one of the initiation sites of the failure. The jagged morphology (close to the notch root) is detected on the fracture surface of Set B and Set C, Figure $3 \mathrm{c}$ and Figure 3e, respectively. The larger jagged region corresponds to the higher toughness (Set $\mathrm{B}$ and Set $\mathrm{C}>\mathrm{Set} \mathrm{A}$ ). This result is consistent with the finding of Nagendra et al. [5] for impact toughness measurement of a La-based BMG.
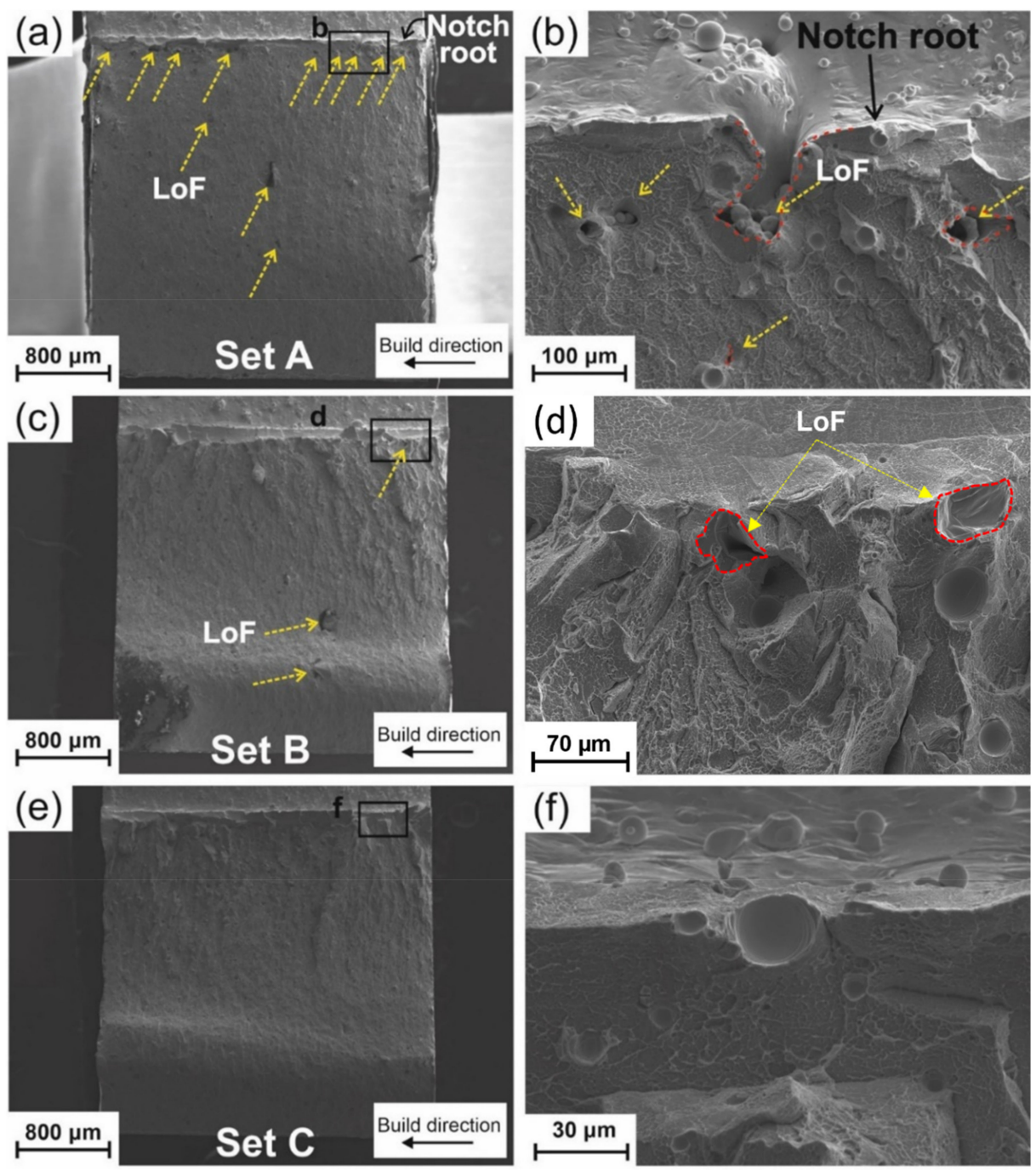

Figure 3. (a) Fracture surface of a Set $A$ impact specimen, (b) higher magnification image of region $b$ in (a), (c) fracture surface of a Set B impact specimen, (d) higher magnification image of region d in (c), (e) fracture surface of a Set $\mathrm{C}$ impact specimen, and (f) higher magnification image of region $\mathrm{f}$ in (e), shear bands were formed inside the large porosity.

Supplementary Materials Figure S2 illustrates a high magnification image from the border (close to the notch) and core of all three Sets, which are representative of the entire fracture surface. Vein-like patterns are evident on the fracture surface, which are attributed to significant softening or reduced viscosity during fracture [44]. However, there is no sign of vein-like patterns in the core of the specimen $(2 \mathrm{~mm}$ far from the notch into the core), where the morphology corresponds to quasi-brittle fracture (see Figure S2b). Unlike ceramics [45] that show very smooth and cleavage fracture surface, dimple-like features 
are detectable in Figure S2b. That is why the fracture mode is here called quasi-brittle. Comparing the near-notch root region for Set A, Set B, and Set C shows that liquid-like features formed in Set $B$ and Set $C$. These features again correlate with the higher impact toughness and less brittle behavior compared to Set A. The liquid-like features indicate local temperature increase due to the sudden release of stored energy [46].

Micro-CT analyses were performed to investigate and quantify defects inside the specimens in 3D. A part of each specimen (from a reduced section of the tensile specimens and $2 \mathrm{~mm}$ away from the notch of the impact specimens) was cut and analyzed, which included both border and core regions. Figure 4 shows 3D constructed (Micro-CT) images from a section of $\left(15.5 \mathrm{~mm}^{3}\right)$ impact specimens. The results of the Micro-CT characterization are summarized in Table 3. The overall density of Set A specimens is lower than Set B and Set $C$, and the number and volume fraction of LoFs is significantly higher for Set $A$ than for Set B and Set C. The two proposed strategies were, therefore, successful in mitigating LoFs. Set $B$ and Set $C$ have similar overall densities, but the number and volume fraction of LoFs is slightly larger for Set B.
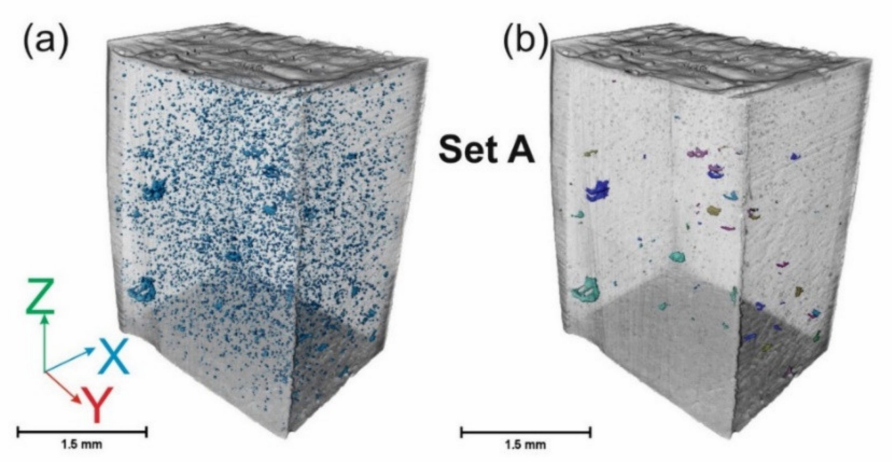

(c)
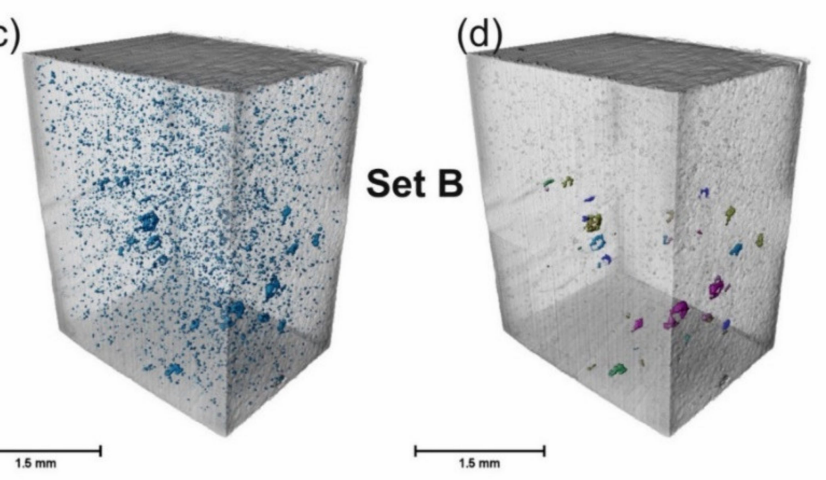

(e)

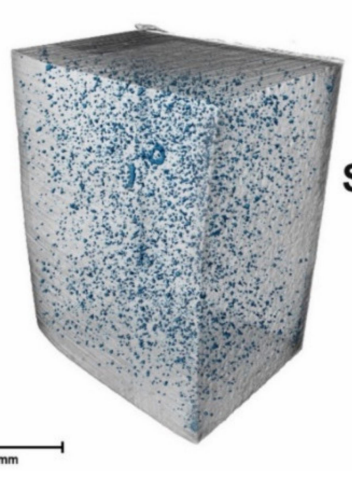

(f)

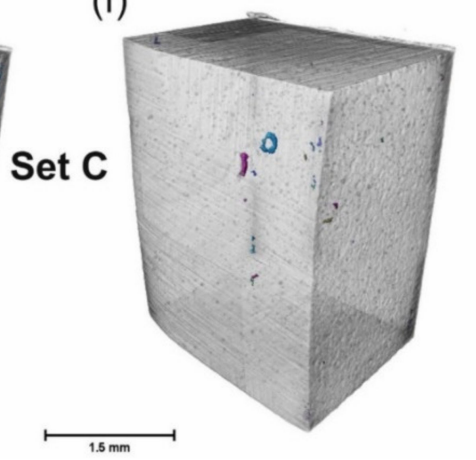

Figure 4. A 3D constructed image of a part of impact specimens $\left(15.5 \mathrm{~mm}^{3}\right)$ fabricated via $(\mathbf{a}, \mathbf{b})$ Set $\mathrm{A}$, $(\mathbf{c}, \mathbf{d})$ Set $\mathrm{B}$, and $(\mathbf{e}, \mathbf{f})$ Set $\mathrm{C}$, using X-ray micro-computed tomography (Micro-CT). Specimens $(\mathbf{a}, \mathbf{c}, \mathbf{e})$ include all defects, while $(\mathbf{b}, \mathbf{d}, \mathbf{f})$ isolate LoFs. All the samples contained border and core regions. 
Table 3. Density of specimens (including both border and core regions), number, and volume fraction of LoFs present in the impact and tensile specimens.

\begin{tabular}{cccc}
\hline Sample & Density (\%) & Number of LoFs & Volume Fraction of LoFs (\%) \\
\hline Impact- Set A & 99.80 & 73 & 0.051 \\
Impact- Set B & 99.85 & 48 & 0.023 \\
Impact- Set C & 99.86 & 46 & 0.007 \\
Tensile- Set A & 99.77 & 129 & 0.068 \\
Tensile- Set B & 99.87 & 38 & 0.014 \\
Tensile- Set C & 99.87 & 34 & 0.009 \\
\hline * Within the resolution of the Micro-CT method.
\end{tabular}

${ }^{*}$ Within the resolution of the Micro-CT method.

\subsection{Tensile Properties}

Tensile tests were carried out with the loading axis perpendicular to the building direction on three specimens for each Set. The tensile yield strength of Set A, B, and C samples are $880 \pm 88 \mathrm{MPa}, 1120 \pm 53 \mathrm{MPa}$, and $1180 \pm 72 \mathrm{MPa}$, respectively (see Figure 5). The corresponding strains to failure are $1.10 \pm 0.15 \%, 1.38 \pm 0.11$, and $1.44 \pm 0.14 \%$. Similar to sample A, no macroscopic plastic deformation was detected in Set B and Set C. As can be seen in Figure 6a (Set A), failure starts from the upper-left corner, which is related to the presence of a near-surface $\operatorname{LoF}$ (Figure 6b). Figure 6c shows an LoF, which may have formed as a result of a large spatter on the surface. Dimple-like features and vein-like patterns are detected in Figure $6 \mathrm{~d}$ and Figure 6e, respectively. Figure $6 \mathrm{f}$ demonstrates a crack-arrest and shear bands multiplication inside the porosity, which can be due to the blunting of the tip of the crack. While Figure $6 \mathrm{~d}$ showed a crack arrest by a porosity, Figure $3 \mathrm{f}$ indicates instead the initiation of a crack close to a porosity, which is open to the surface. This underlines the effect of size, shape, location, and distribution of porosities in determining their beneficial or detrimental influence on mechanical properties. Figure $6 \mathrm{~g}$ shows the fracture surface of Set $C$ and the directions of the crack propagation (white arrows). The crack started from the right edge of the specimen. Figure $6 \mathrm{~h}$ shows a higher magnification of the crack initiation location (region $\mathrm{h}$ in Figure 6g). A small near-surface LoF is detected and corresponds to the crack initiation site.

Micro-CT images of the tensile specimens are presented in Supplementary Materials Figure S3, the summary being presented in Table 3, with trends similar to those of impact samples.

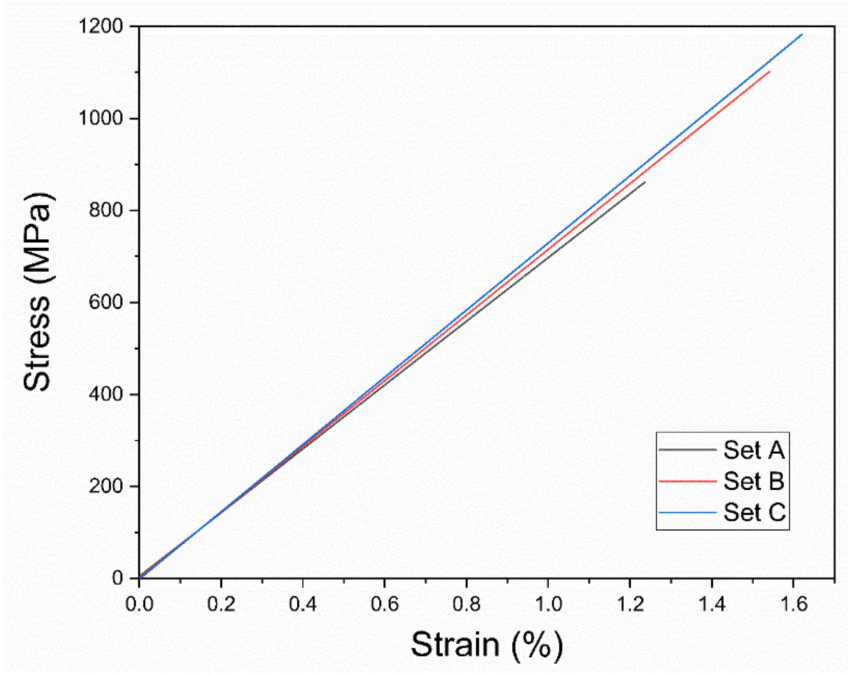

Figure 5. Stress-strain curve of tensile tests for Sets A-C. 

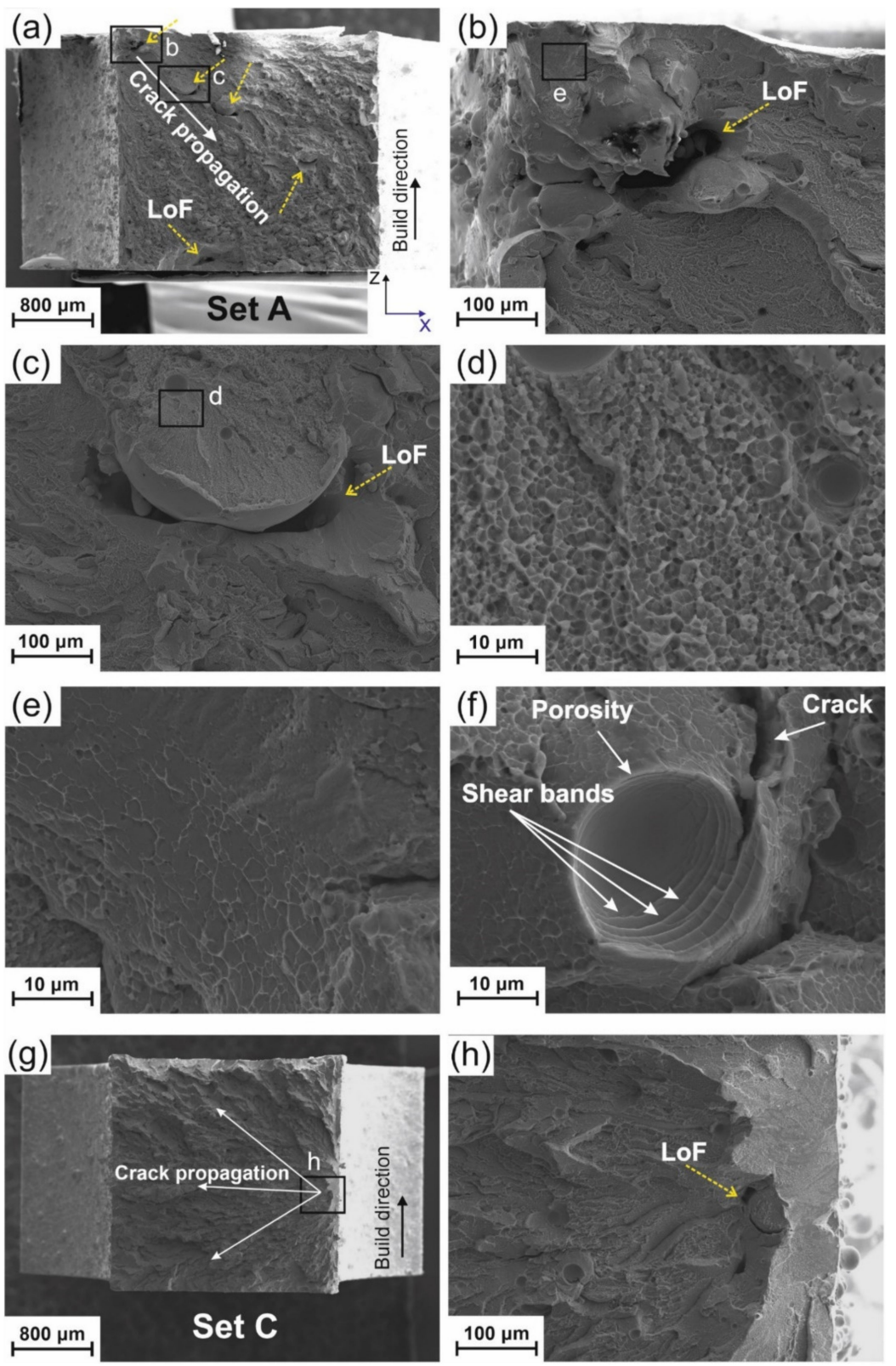

Figure 6. (a) Fracture surface (X-Z plane) of a tensile specimen Set A after rupture. Yellow-dashed arrows show LoFs. (b) Region $b$ in (a) with a higher magnification showing the start of failure from a lack of fusion (LoF), (c) region c in (a) with a higher magnification indicating another LoF, (d) region $\mathrm{d}$ in (c) with a higher magnification showing dimple-like features, (e) region e in (b) with a higher magnification indicating vein-like patterns, (f) a porosity arrests a crack and multiple shear bands are found, (g) fracture surface (X-Z plane) of a tensile specimen $C$, and (h) region h shown in (g) with a higher magnification.

\section{Discussion}

The increased amount of crystallization for Sets $B$ and $C$ compared to Set $A$ is attributed to the higher power used for printing the border ( $40 \%$ higher) and the core (20\% higher). As power increases, the input energy increases consequently, and the BMG is more prone to crystallization [31,43]. Although XRD could not detect crystallization for Set A, the increased crystallized fraction measured by DSC from Sets A to C is in agreement with the XRD results. In our previous work [47], using fast scanning calorimetry, we showed that the thermal stability of AMZ4 is low and that the time to crystallization at the nose of the 
time-temperature-transformation (TTT) diagram is less than $4 \mathrm{~ms}$, which is sufficient for the formation of nanocrystals during the LPBF process.

Deng et al. [48] investigated the effect of density on the compression strength of a CuZr-based BMG composite fabricated via LPBF. They showed that the compression strength increased with an increase in the density of the samples. However, they did not differentiate between the core and near-surface defects. For crystalline materials [49,50], it has been shown that near-surface defects are the most detrimental ones. It is confirmed here that for BMGs as well, such defects, especially those that are in near-surface regions and with a convoluted shape (LoF in Figure $3 b$ ), decrease the strength and toughness of the specimen. Only changing the border laser power (comparing Set A and Set B) resulted in a $28 \%$ improvement in the impact toughness, while only changing the core power (comparing Set B and Set C) resulted in a 3\% improvement. The 3\% increase is not significant considering the statistical scatter of the results. The priority is then in removing sub-surface defects, in agreement with Ref. [50]. The number of LoFs (Table 3) is not highly affected as the core power increases (comparing Set B and Set C), but their size is reduced, which lowers the volume fraction of the LoFs (see Figure 4). However, higher core power increases the amount of 'spherical' porosities (not considered as LoFs), which explains the very similar densities of Set B and Set C samples, in agreement with Ref [48].

It had been previously shown that using higher laser power leads to an increased amount of crystallization, with a detrimental effect on resistance to cracking [31]. Bordeenithikasem et al. [15] showed that crystallization of AMZ4 resulted in the increase of brittleness and reduction of flexural strength. In addition, Pacheco et al. [41] and Marattukalam et al. [43] detected crystallization in AMZ4. However, there is no report on the formation of ductile crystals during the crystallization of AMZ4 in the literature, which could improve the ductility of the fabricated parts. The present study shows, however, that removing defects (mainly LoFs) and increasing crystallization does improve the impact toughness, overall. This assertion is valid for specimens with crystallized fractions up to $17 \%$ (Set C). Higher levels of crystallization have not been investigated in the current study but are reported in Table S1 from other studies.

There is no literature study on the impact toughness of either BMGs fabricated via AM methods or AMZ4 fabricated by other conventional methods such as casting. The latter would be of interest to establish reference properties to which our LPBF BMGs could be compared. The results of this study are therefore compared with those from other BMGs fabricated by casting and semi-solid forged, in Supplementary Materials Table S1. Our results indicate values lower than those of amorphous Zr-based BMGs [7-11] and Al-alloys [10], but close to those of Zr-based annealed samples in Refs [7-9]. The notch in the as-cast samples was prepared by precise machining, whereas in the current study, it was included in the LPBF fabrication. The notch curvature of the specimens was slightly higher than the nominal value due to the limited resolution of the LPBF process and might overestimate the absolute values of measured impact toughness. However, the presence of the roughness inherent to the LPBF process in the as-built condition could result in stress concentration, which would then lead to underestimating the impact toughness results. It is understood that comparing the absolute value of impact toughness for specimens with different geometries, test methods, and fabrication methods cannot provide a clear ranking as long as the values are in the same order of magnitude. Some of the BMG composites containing a ductile crystalline phase $[10,11]$ showed enhanced impact toughness, even higher than that of Ti-6Al-4V [10]. In general, however, unwanted crystallization [5] and annealing [6-9] dramatically reduced the impact toughness.

Best et al. [33] studied the effect of the oxygen content in BMGs on fracture toughness. Although lab-grade ( 170 ppm oxygen content) and industrial-grade ( 1300 ppm oxygen content) samples had similar hardness and compressive strength, the lab-grade sample had a five times higher fracture toughness. The authors correlated this behavior to the dissolved oxygen content, which acts as a barrier for atomic movement and reduces toughness. Yokoyama et al. [51] also commented on the deleterious effect of oxygen on the 
impact toughness of a Zr-based BMG. The oxygen content of LPBF parts was measured as $1480 \mathrm{ppm}$ in our previous work [27]. According to Lin et al. [36], annealing was the reason for the absence of ductility in a compression test of a BMG fabricated via DED. A combination of partial crystallization, high oxygen content, annealing, and the presence of printing defects all potentially explain the low measured values of impact toughness in the present study.

No macroscopic plastic deformation was detected in the tensile tests (Figure 5), in agreement with Refs $[35,36]$. Lin et al. [36] correlated this behavior to the annealing effect, which happens in laser-based AM processes because of the associated cyclic heating. The formation of dimples is caused by the nano-scaled cavitation in the quasi-brittle fracture $[52,53]$. The change of features morphology on the fracture surface from veinlike patterns to dimples correspond to a transition of the fracture mode from ductile to quasi-brittle [54].

Since there is only one reported study [33] on the tensile properties of BMGs fabricated via LPBF, the present results were also compared to properties measured on BMGs fabricated via other AM methods, such as DED [34-37]. Figure 7 plots our AMZ4 results together with those of Ref. [33], and four other Zr-based BMGs [34-37]. It is assumed that in Ref. [33], the tensile samples were ground before testing since no printing pattern can be observed on the external surface. The reason for the slightly lower tensile strength in Ref. [33] compared to Set B and Set C can be attributed to the presence of large and irregular porosities (LoFs) in the printed samples, which Best et al. [33] showed by providing a Micro-CT image. Although our AMZ4 specimens were in "semi-as-built" condition (without any surface finishing), whereas the tensile specimens in Refs [34-37] were in a surface finished state, the present results position themselves among the best ones for BMGs fabricated via AM processes. Therefore, AMZ4 manufactured via LPBF can be a good candidate for applications where a high tensile yield strength is required.

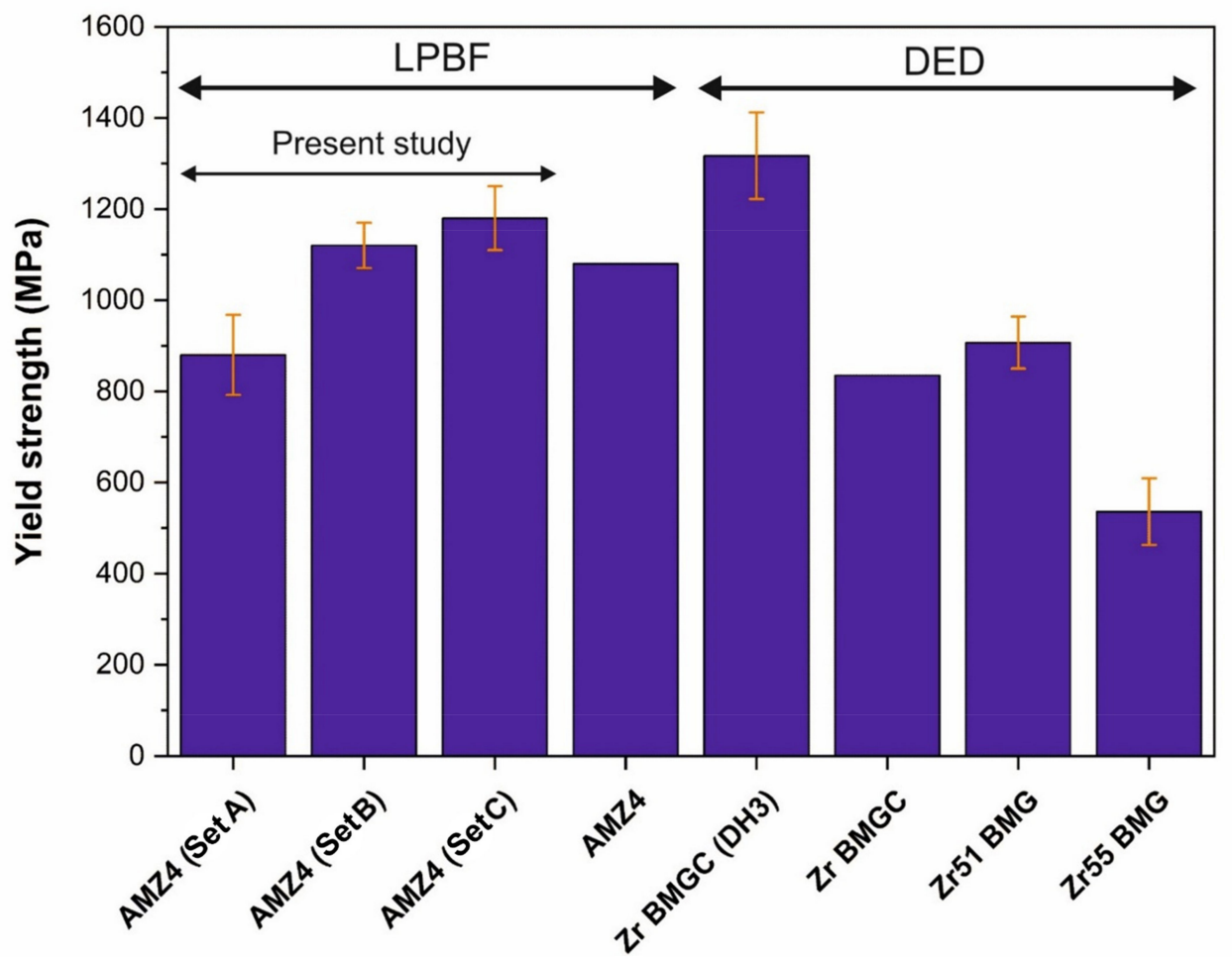

Figure 7. Comparison of tensile yield strengths in the present study with a LPBF manufactured AMZ4 [33], and with DH3 $\left(\mathrm{Zr}_{39.6} \mathrm{Ti}_{33.9} \mathrm{Nb}_{7.6} \mathrm{Cu}_{6.4} \mathrm{Be}_{12.5}\right)$ [37], $\mathrm{Zr}$ BMG composite $\left(\mathrm{Zr}_{39.6} \mathrm{Ti}_{33.9} \mathrm{Nb}_{7.6} \mathrm{Cu}_{6.4} \mathrm{Be}_{12.5}\right)$ [34], $\mathrm{Zr} 51$ BMG $\left(\mathrm{Zr}_{51} \mathrm{Ti}_{5} \mathrm{Ni}_{10} \mathrm{Cu}_{25} \mathrm{Al}_{9}\right)$ [35], and $\mathrm{Zr55}$ BMG $\left(\mathrm{Zr}_{55} \mathrm{Cu}_{30} \mathrm{Al}_{10} \mathrm{Ni}_{5}\right.$ ) [36] fabricated via direct energy deposition (DED). 
LoFs were present in both impact and tensile specimens, and the near-surface LoFs were identified as the primary reason for premature failure. This is in agreement with the finding of Best et al. [33] and Su et al. [34], who showed that printing defects resulted in low tensile strength of BMGs fabricated via AM processes. In addition, near-surface defects are also known as "critical crack initiation pores" [49,50]. Going from sample A to $B$ leads to a $27 \%$ of improvement in the yield strength, while sample $C$ improves only by $5 \%$ compared to Set B (see Figure 7). Due to the statistical scatter of the tensile results around $5 \%$, the improvement is not considered to be significant. Both tensile and impact toughness results show the importance of eliminating/mitigating the near-surface defects, in particular the LoFs.

\section{Conclusions}

In this work, crack-free Zr-based bulk metallic glass (BMG) specimens were fabricated via laser powder-bed fusion (LPBF). Tensile and impact toughness properties of the fabricated specimens were investigated in the "semi-as-built" state. The following conclusions could be reached:

- Using the first strategy (increasing the laser power in the border region) led to the mitigation of near-surface LoFs, and the results showed around $27 \%$ improvement in the tensile yield strength and impact toughness. Changing only the core laser power (second strategy) resulted in only $5 \%$ and 3\% improvement in the tensile yield strength and impact toughness, respectively, compared to the first strategy, which are not considered to be significant.

- It was confirmed that, for additively manufactured BMGs, near-surface defects such as lack of fusions (LoFs) are more critical than those present in the core of the specimens.

- Although implementing the two mentioned strategies increased crystallization (up to $17 \%$ ) because of the higher laser power, the importance of reducing porosity defects (especially LoFs) prevailed. The tensile yield strength of the Zr-based BMG was one of the best ones among those reported for BMGs fabricated via additive manufacturing (AM).

Supplementary Materials: The following are available online at https:/ /www.mdpi.com/article/10

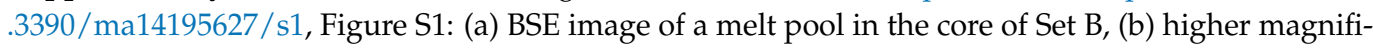
cation of region $b$ in (a), (c) BSE image of a melt pool in the border of Set B, (d) higher magnification of region $d$ in (c), (e) BSE image of a melt pool in the core of Set C, (f) higher magnification of region $f$ in (e), (g) BSE image of a melt pool in the border of Set C, and (h) higher magnification of region $\mathrm{h}$ in (g), Figure S2: High magnification image of the fracture surface of the impact specimens fabricated via $(\mathrm{a}, \mathrm{b})$ Set $\mathrm{A},(\mathrm{c}, \mathrm{d})$ Set $\mathrm{B}$, and $(\mathrm{e}, \mathrm{f})$ Set $\mathrm{C}$. The border region images $(\mathrm{a}, \mathrm{c}, \mathrm{e})$ show vein-like patterns. For (c,e), which have higher impact toughness, molten particles are detected (yellow arrows). The images from the core region $(b, d, f)$ are similar to each other, which shows that rapid fracture leads to similar fracture surface morphology. The images related to the core $(\mathrm{b}, \mathrm{d}, \mathrm{f})$ were taken $2 \mathrm{~mm}$ away from the notch, and into the core of the sample, Figure S3: A 3D constructed image of a part of tensile specimens fabricated via $(\mathrm{a}, \mathrm{b})$ Set $\mathrm{A},(\mathrm{c}, \mathrm{d})$ Set $\mathrm{B}$, and $(\mathrm{e}, \mathrm{f})$ Set $\mathrm{C}$ using $\mathrm{X}$-ray micro-computed tomography (Micro-CT). (a,c,e) Include all defects, but (b,d,f) just shows LoFs, Table S1: Comparison of impact toughness measured in the present study with other BMGs fabricated via conventional methods, such as casting and semi-solid forging.

Author Contributions: Conceptualization, N.S. and R.E.L.; methodology, N.S. and A.P.; validation, J.J. and R.E.L.; formal analysis, N.S., A.P., and A.N.; investigation, N.S. and A.P.; resources, R.E.L.; data curation, A.P.; writing—original draft preparation, N.S.; writing—review and editing, A.P., J.J., A.N., and R.E.L.; visualization, N.S. and A.P.; supervision, R.E.L.; project administration, R.E.L.; funding acquisition, R.E.L. All authors have read and agreed to the published version of the manuscript.

Funding: This work was supported by the "PREcision Additive Manufacturing of Precious metals Alloys (PREAMPA)" project. The PREAMPA project is funded by the Swiss ETH domain, within the Strategic Focus Area on Advanced Manufacturing.

Institutional Review Board Statement: Not applicable. 
Informed Consent Statement: Not applicable.

Data Availability Statement: The raw/processed data required to reproduce these findings cannot be shared at this time as the data also forms part of an ongoing study.

Acknowledgments: The generous support of PX Group to the LMTM laboratory is also highly acknowledged. The authors would like to thank Cyril Dénéréaz, Vaclav Pejchal, and Hossein Ghasemi-Tabasi for their help in performing impact and tensile tests. The authors would also like to express their gratitude to Milad Hamidi-Nasab for the fruitful discussions.

Conflicts of Interest: The authors declare no conflict of interest.

\section{References}

1. Schroers, J. Processing of Bulk Metallic Glass. Adv. Mater. 2010, 22, 1566-1597. [CrossRef] [PubMed]

2. Zhang, Z.F.; Eckert, J.; Schultz, L. Difference in compressive and tensile fracture mechanisms of $\mathrm{Zr}_{59} \mathrm{Cu}_{20} \mathrm{Al}_{10} \mathrm{Ni}_{8} \mathrm{Ti}_{3}$ bulk metallic glass. Acta Mater. 2003, 51, 1167-1179. [CrossRef]

3. Szuecs, F.; Kim, C.P.; Johnson, W.L. Mechanical properties of $\mathrm{Zr}_{56.2} \mathrm{Ti}_{13.8} \mathrm{Nb}_{5.0} \mathrm{Cu}_{6.9} \mathrm{Ni}_{5.6} \mathrm{Be}_{2.5}$ ductile phase reinforced bulk metallic glass composite. Acta Mater. 2001, 49, 1507-1513. [CrossRef]

4. Ning, Z.; Liang, W.; Zhang, M.; Li, Z.; Sun, H.; Liu, A.; Sun, J. High tensile plasticity and strength of a CuZr-based bulk metallic glass composite. Mater. Des. 2016, 90, 145-150. [CrossRef]

5. Nagendra, N.; Ramamurty, U.; Goh, T.T.; Li, Y. Effect of crystallinity on the impact toughness of a La-based bulk metallic glass. Acta Mater. 2000, 48, 2603-2615. [CrossRef]

6. Ramamurty, U.; Lee, M.L.; Basu, J.; Li, Y. Embrittlement of a bulk metallic glass due to low-temperature annealing. Scr. Mater. 2002, 47, 107-111. [CrossRef]

7. Murali, P.; Ramamurty, U. Embrittlement of a bulk metallic glass due to sub-Tg annealing. Acta Mater. 2005, 53, 1467-1478. [CrossRef]

8. Raghavan, R.; Murali, P.; Ramamurty, U. Ductile to brittle transition in the $\mathrm{Zr}_{41.2} \mathrm{Ti}_{13.75} \mathrm{Cu}_{12.5} \mathrm{Ni}_{10} \mathrm{Be}_{22.5}$ bulk metallic glass. Intermetallics 2006, 14, 1051-1054. [CrossRef]

9. Raghavan, R.; Murali, P.; Ramamurty, U. On factors influencing the ductile-to-brittle transition in a bulk metallic glass. Acta Mater. 2009, 57, 3332-3340. [CrossRef]

10. Zachrisson, C.; Kozachkov, H.; Roberts, S.; Kaltenboeck, G.; Conner, R.D.; Demetriou, M.D.; Johnson, W.L.; Hofmann, D.C. Effect of processing on Charpy impact toughness of metallic glass matrix composites. Mater. Res. 2011, 26, 1260-1268. [CrossRef]

11. Roberts, S.; Zachrisson, C.; Kozachkov, H.; Ullah, A.; Shapiro, A.A.; Johnson, L.; Hofmann, D.C. Cryogenic Charpy impact testing of metallic glass matrix composites. Scr. Mater. 2012, 66, 284-287. [CrossRef]

12. Yokoyama, Y.; Fukaura, K.; Inoue, A. Cast structure and mechanical properties of $\mathrm{Zr}-\mathrm{Cu}-\mathrm{Ni}-\mathrm{Al}$ bulk glassy alloys. Intermetallics 2002, 10, 1113-1124. [CrossRef]

13. Keryvin, V.; Bernard, D.; Sangleboeuf, J.C.; Yokoyama, Y.; Rouxel, T. Toughness of $\mathrm{Zr}_{41.2} \mathrm{Ti}_{13.75} \mathrm{Cu}_{12.5} \mathrm{Ni}_{10} \mathrm{Be}_{22.5}$ bulk metallic glass for two oxygen levels. Non-Crytalline Solids 2006, 352, 2863-2868. [CrossRef]

14. Best, J.P.; Ast, J.; Li, B.; Stolpe, M.; Busch, R.; Yang, F.; Li, X.; Michler, J.; Kruzic, J.J. Relating fracture toughness to micro-pillar compression response for a laser powder bed additive manufactured bulk metallic glass. Mater. Sci. Eng. A 2020, $770,138535$. [CrossRef]

15. Bordeenithikasem, P.; Stolpe, M.; Elsen, A.; Hofmann, D.C. Glass forming ability, flexural strength, and wear properties of additively manufactured Zr-based bulk metallic glasses produced through laser powder bed fusion. Addit. Manuf. 2018, 21, 312-317. [CrossRef]

16. DebRoy, T.; Wei, H.L.; Zuback, J.S.; Mukherjee, T.; Elmer, J.W.; Milewski, J.O.; Beese, A.M.; Wilson-Heid, A.; De, A.; Zhang, W. Additive manufacturing of metallic components-Process, structure and properties. Prog. Mater. Sci. 2018, 92, 112-224. [CrossRef]

17. Sohrabi, N.; Jhabvala, J.; Logé, R.E. Additive Manufacturing of Bulk Metallic Glasses-Process, Challenges and Properties: A Review. Metals 2021, 11, 1279. [CrossRef]

18. Vilaro, T.; Kottman-Rexerodt, V.; Thomas, M.; Colin, C.; Bertrand, P.; Thivillon, L.; Abed, S.; Ji, V.; Aubry, P.; Peyre, P.; et al. Direct Fabrication of a Ti-47Al-2Cr-2Nb Alloy by Selective Laser Melting and Direct Metal Deposition Processes. Adv. Mater. Res. 2010, 89, 586-591. [CrossRef]

19. Löffler, J.F. Bulk metallic glasses. Intermetallics 2003, 11, 529-540. [CrossRef]

20. Sohrabi, N.; Jhabvala, J.; Kurtuldu, G.; Frison, R.; Parrilli, A.; Stoica, M.; Neels, A.; Löffler, J.F.; Logé, R.E. Additive manufacturing of a precious bulk metallic glass. Appl. Mater. Today 2021, 24, 101080. [CrossRef]

21. Prashanth, K.G.; Shakur Shahabi, H.; Attar, H.; Srivastava, V.C.; Ellendt, N.; Uhlenwinkel, V.; Eckert, J.; Scudino, S. Production of high strength Al85Nd8Ni5Co2 alloy by selective laser melting. Addit. Manuf. 2015, 6, 1-5. [CrossRef]

22. Lu, X.; Nursulton, M.; Du, Y.; Liao, W. Structural and mechanical characteristics of Cu50Zr43Al7 bulk metallic glass fabricated by selective laser melting. Materials 2019, 12, 775. [CrossRef] [PubMed] 
23. Deng, L.; Wang, S.; Wang, P.; Kühn, U.; Pauly, S. Selective laser melting of a Ti-based bulk metallic glass. Mater. Lett. 2018, 212, 346-349. [CrossRef]

24. Pauly, S.; Löber, L.; Petters, R.; Stoica, M.; Scudino, S.; Kühn, U.; Eckert, J. Processing Metallic Glasses by Selective Laser Melting. Mater. Today 2013, 16, 37-41. [CrossRef]

25. Jung, H.Y.; Choi, S.J.; Prashanth, K.G.; Stoica, M.; Scudino, S.; Yi, S.; Kühn, U.; Kim, D.H.; Kim, K.B.; Eckert, J. Fabrication of Fe-based bulk metallic glass by selective laser melting: A parameter study. Mater. Des. 2015, 86, 703-708. [CrossRef]

26. Ouyang, D.; Xing, W.; Li, N.; Li, Y.; Liu, L. Structural evolutions in 3D-printed Fe-based metallic glass fabricated by selective laser melting. Addit. Manuf. 2018, 23, 246-252. [CrossRef]

27. Sohrabi, N.; Jhabvala, J.; Kurtuldu, G.; Stoica, M.; Parrilli, A.; Berns, S.; Polatidis, E.; Van Petegem, S.; Hugon, S.; Neels, A.; et al. Characterization, mechanical properties and dimensional accuracy of a Zr-based bulk metallic glass manufactured via laser powder-bed fusion. Mater. Des. 2021, 199, 109400. [CrossRef]

28. Gao, X.; Liu, Z.; Li, J.; Liu, E.; Yue, C.; Zhao, K.; Yang, G. Selective laser melting of CuZr-based metallic glass composites. Mater. Lett. 2020, 259, 126724. [CrossRef]

29. Li, X.P.; Roberts, M.P.; O'Keeffe, S.; Sercombe, T.B. Selective laser melting of Zr-based bulk metallic glasses: Processing, microstructure and mechanical properties. Mater. Des. 2016, 112, 217-226. [CrossRef]

30. Zhang, C.; Li, X.M.; Liu, S.Q.; Liu, H.; Yu, L.J.; Liu, L. 3D printing of Zr-based bulk metallic glasses and components for potential biomedical applications. J. Alloys Compd. 2019, 790, 963-973. [CrossRef]

31. Sohrabi, N.; Panikar, R.S.; Jhabvala, J.; Buch, A.R.; Mischler, S.; Logé, R.E. Laser coating of a Zr-based metallic glass on an aluminum substrate. Surf. Coatings Technol. 2020, 400. [CrossRef]

32. Sohrabi, N.; Hamidi-Nasab, M.; Rouxel, B.; Jhabvala, J.; Parrilli, A.; Vedani, M.; Logé, R.E. Fatigue Performance of an Additively Manufactured Zr-Based Bulk Metallic Glass and the Effect of Post-Processing. Metals 2021, 11, 1064. [CrossRef]

33. Best, J.P.; Ostergaard, H.E.; Li, B.; Stolpe, M.; Yang, F.; Nomoto, K.; Hasib, M.T.; Muránsky, O.; Busch, R.; Li, X.; et al. Fracture and fatigue behaviour of a laser additive manufactured Zr-based bulk metallic glass. Addit. Manuf. 2020, 36, 101416. [CrossRef]

34. Su, S.; Lu, Y. Laser directed energy deposition of Zr-based bulk metallic glass composite with tensile strength. Mater. Lett. 2019, 247, 79-81. [CrossRef]

35. Zhai, L.; Lu, Y.; Zhao, X.; Wang, L.; Lu, X. High-throughput screening of laser additive manufactured metallic glass via ultrasonic wave. Sci. Rep. 2019, 9, 17660. [CrossRef]

36. Lin, X.; Zhang, Y.; Yang, G.; Gao, X.; Hu, Q.; Yu, J.; Wei, L.; Huang, W. Microstructure and compressive/tensile characteristic of large size Zr-based bulk metallic glass prepared by laser solid forming. J. Mater. Sci. Technol. 2019, 35, 328-335. [CrossRef]

37. Lu, Y.; Su, S.; Zhang, S.; Huang, Y.; Qin, Z.; Lu, X.; Chen, W. Controllable additive manufacturing of gradient bulk metallic glass composite with high strength and tensile ductility. Acta Mater. 2021, 206, 116632. [CrossRef]

38. Berg, M.T.L.; Bromiley, G.D.; Butler, I.B.; Frost, M.; Bradley, R.; Carr, J.; Le, Y.; Montési, L.G.J.; Zhu, W.; Miller, K.; et al. Deformation-aided segregation of Fe-S liquid from olivine under deep Earth conditions: Implications for core formation in the early solar system. Phys. Earth Planet. Inter. 2017, 263, 38-54. [CrossRef]

39. Karimi, P.; Schnur, C.; Sadeghi, E.; Andersson, J. Contour design to improve topographical and microstructural characteristics of Alloy 718 manufactured by electron beam-powder bed fusion technique. Addit. Manuf. 2020, 32, 101014. [CrossRef]

40. Cui, X.; Zu, F.Q.; Wang, Z.Z.; Huang, Z.Y.; Li, X.Y.; Wang, L.F. Study of the reversible intermetallic phase: B2-type CuZr. Intermetallics 2013, 36, 21-24. [CrossRef]

41. Pacheco, V.; Karlsson, D.; Marattukalam, J.J.; Stolpe, M.; Hjörvarsson, B.; Jansson, U.; Sahlberg, M. Thermal stability and crystallization of a $\mathrm{Zr}$-based metallic glass produced by suction casting and selective laser melting. J. Alloys Compd. 2020, 825, 153995. [CrossRef]

42. Baricco, M.; Spriano, S.; Chang, I.; Petrzhik, M.I.; Battezzati, L. “Big cube” phase formation in Zr-based metallic glasses. Mater. Sci. Eng. A 2001, 304-306, 305-310. [CrossRef]

43. Marattukalam, J.J.; Pacheco, V.; Karlsson, D.; Riekehr, L.; Lindwall, J.; Forsberg, F.; Jansson, U.; Sahlberg, M.; Hjörvarsson, B. Development of process parameters for selective laser melting of a Zr-based bulk metallic glass. Addit. Manuf. 2020, 33,101124 . [CrossRef]

44. Dalla Torre, F.H.; Dubach, A.; Schällibaum, J.; Löffler, J.F. Shear striations and deformation kinetics in highly deformed Zr-based bulk metallic glasses. Acta Mater. 2008, 56, 4635-4646. [CrossRef]

45. Lawn, B. Fracture of Brittle Solids, 2nd ed.; Cambridge University Press: Cambridge, UK, 1993; ISBN 9780521409728.

46. Bruck, H.A.; Rosakis, A.J.; Johnson, W.L. The dynamic compressive behavior of beryllium bearing bulk metallic glasses. J. Mater. Res. 1996, 11, 503-511. [CrossRef]

47. Sohrabi, N.; Schawe, J.E.K.; Jhabvala, J.; Löffler, J.F.; Logé, R.E. Critical crystallization properties of an industrial-grade Zr-based metallic glass used in additive manufacturing. Scr. Mater. 2021, 199, 113861. [CrossRef]

48. Deng, L.; Zhang, L.; Kosiba, K.; Limbach, R.; Wondraczek, L.; Wang, G.; Gu, D.; Kühn, U.; Pauly, S. CuZr-based bulk metallic glass and glass matrix composites fabricated by selective laser melting. J. Mater. Sci. Technol. 2021, 81, 139-150. [CrossRef]

49. Du Plessis, A.; Yadroitsava, I.; Yadroitsev, I. Effects of defects on mechanical properties in metal additive manufacturing: A review focusing on X-ray tomography insights. Mater. Des. 2020, 187, 108385. [CrossRef] 
50. Andreau, O.; Pessard, E.; Koutiri, I.; Penot, J.-D.; Dupuy, C.; Saintier, N.; Peyre, P. A competition between the contour and hatching zones on the high cycle fatigue behaviour of a 316L stainless steel: Analyzed using X-ray computed tomography. Mater. Sci. Eng. A 2019, 757, 146-159. [CrossRef]

51. Yokoyama, Y.; Kobayashi, A.; Fukaura, K.; Inoue, A. Oxygen Embrittlement and Effect of the Addition of Ni Element in a Bulk Amorphous Zr-Cu-Al Alloy. Mater. Trans. 2002, 43, 571-574. [CrossRef]

52. Murali, P.; Narasimhan, R.; Guo, T.F.; Zhang, Y.W.; Gao, H.J. Shear bands mediate cavitation in brittle metallic glasses. Scr. Mater. 2013, 68, 567-570. [CrossRef]

53. Murali, P.; Guo, T.F.; Zhang, Y.W.; Narasimhan, R.; Li, Y.; Gao, H.J. Atomic Scale Fluctuations Govern Brittle Fracture and Cavitation Behavior in Metallic Glasses. Phys. Rev. Lett. 2011, 107, 215501. [CrossRef] [PubMed]

54. Jia, H.; Wang, G.; Chen, S.; Gao, Y.; Li, W.; Liaw, P.K. Fatigue and fracture behavior of bulk metallic glasses and their composites. Prog. Mater. Sci. 2018, 98, 168-248. [CrossRef] 